\title{
Effect of an educational
}

\section{intervention on knowledge and attitude regarding pharmacovigilance and consumer pharmacovigilance among community pharmacists in Lalitpur district, Nepal}

Nisha Jha ${ }^{*}$, Devendra Singh Rathore ${ }^{2}$, Pathiyil Ravi Shankar ${ }^{3}$, Shital Bhandary ${ }^{4}$, Rabi Bushan Pandit ${ }^{5}$, Sudesh Gyawali' ${ }^{6}$ and Mohamed Alshakka ${ }^{7}$

\begin{abstract}
Background: Pharmacovigilance activities are in a developing stage in Nepal. ADR reporting is mainly confined to healthcare professionals working in institutions recognized as regional pharmacovigilance centers. Community pharmacists could play an important role in pharmacovigilance. This study was conducted among community pharmacists in Lalitpur district to examine their knowledge and attitude about pharmacovigilance before and after an educational intervention.

Methods: Knowledge and attitude was studied before, immediately after and 6 weeks following the intervention among 75 community pharmacists. Responses were analysed using descriptive and inferential statistics. A pretested questionnaire having twelve and nine statements for assessing knowledge and attitude were used. The overall scores were obtained by adding the 'knowledge' and 'attitude' scores and 'overall' scores were summarized using median and interquartile range. Wilcoxon signed-rank test for repeated samples was used to compare the differences between knowledge and attitude of the pharmacists before and after the educational program.
\end{abstract}

Results: Knowledge scores [median (interquartile range)] improved significantly between pre-test [39 (44-46)], post-test [44 (44-44)] and retention period of 6 weeks after the intervention [46 (43-46)]. Knowledge score improved immediately post-intervention among both males [44 (41-47)] and females [44 (43-45)] but the retention scores (after 6 weeks) were higher [46 (42-48)] among males. Attitude scores improved significantly among females [46 (44-48)]. The overall scores were higher among pharmacists from rural areas.

Conclusion: Knowledge and attitude scores improved after the educational intervention. Further studies in other regions of the country are required. The national pharmacovigilance center should promote awareness about ADR reporting among community pharmacists.

Keywords: Adverse drug reaction, Community pharmacists, Nepal, Pharmacovigilance, Reporting systems

*Correspondence: nishajha32@gmail.com

${ }^{1}$ Department of Clinical Pharmacology and Therapeutics, KIST Medical

College, Lalitpur, Nepal

Full list of author information is available at the end of the article 


\section{Background}

Adverse drug reactions (ADRs) can be a serious threat to the health of the Nepalese population as a variety of medicines like, allopathic, traditional, homeopathic and ayurvedic are available in ever increasing amounts. Strengthening the ADR reporting system, and making ADR reporting by health professionals mandatory can be useful but unfortunately reporting is not mandatory according to the laws and regulations of Nepal [1]. Voluntary reporting of ADRs by healthcare professionals (HCPs) is limited [2]. There is no involvement of community pharmacists (CPs) in the existing ADR reporting system [3]. In the Pokhara valley in western Nepal, a pilot program was conducted to train selected CPs in ADR reporting and pharmacovigilance [4]. During the study period 71 ADRs were reported by the CPs. However, there has been no further development of ADR reporting by CPs.

Nepal is situated between India and China and is divided into mountainous region, hilly region and plain terrain. The difficult terrain causes problems for the population in accessing healthcare facilities. The total population of Nepal in 2011 was 26.5 million [3]. The GDP per capita was US\$ 562. Population below 15 years was $37 \%$ and above 60 years was $6 \%$ of the total population [5]. Urban population was $28.1 \%$ of the total population [6]. Adult literacy rate was $65.9 \%$ [7].

Nepal produces a significant number of doctors and other health personnel but only a low number stay back as they get better opportunities in the developed world. This brain drain has resulted in a very poor doctor population, pharmacist population and nurse population ratio. There are 10,197 (3.64/10,000 population) medical and dental doctors, 32,846 (11.71/10,000 population) nursing and midwifery personnel and $731(0.261 / 10,000$ population) licensed pharmacists in Nepal [8]. This low ratio of HCP to patients can result in increased workload creating difficulty in sparing time for ADR reporting. This could be an important reason for underreporting by HCPs in Nepal. Underreporting remains a big problem worldwide among HCPs [9-11]. The pharmacist population ratio in Nepal is $0.3 / 10,000$ while the community pharmacist population ratio is only $0.013 / 10,000$ [8].

\section{Pharmacy practice in the community}

Doctors do not practice in many remote and rural areas of Nepal. The population depends on local practitioners and community pharmacies for healthcare and a large number of community pharmacies have been established. The number of pharmacies is greater than the number of health centres $[12,13]$. Community pharmacists do not charge consultation fees unlike medical doctors. This may be a factor responsible for these pharmacies being the first point of contact with the healthcare system for the general public. These factors support and encourage self-medication in the country $[13,14]$ which may increase the incidence of ADRs.

The number of qualified pharmacists in community pharmacies, capable of delivering quality pharmaceutical services is inadequate [15]. As per the Drug Act of 1978, pharmacists, assistant pharmacists and pharmacy professionals are eligible to work in a community pharmacy after registering with the national drug regulatory authority, the Department of Drug Administration (DDA) [16].

Pharmacists working in community pharmacies have completed either a three year Diploma in Pharmacy (DPharm) after ten years of schooling (assistant pharmacists), or four year Bachelor in Pharmacy (BPharm) degree after twelve years of schooling (pharmacists). However, some have only completed a training and orientation program of 2 weeks, conducted by DDA (pharmacy professionals) $[17,18]$. Only pharmacists and assistant pharmacists are eligible for registering with the Pharmacy Council of Nepal [19].

In Nepal with a high prevalence of self-medication and non-doctor prescribing, it is important to expand the existing pharmacovigilance system to involve community pharmacists $[1,14,20]$. A community-based ADR reporting system can play an active role in collecting reports of ADRs occurring in the community $[3,4]$.

\section{Pharmacovigilance activities in Nepal}

Nepal was recognized as a member of the International Pharmacovigilance Programme in 2007. The national pharmacovigilance centre run by the DDA, coordinates with seven regional pharmacovigilance centres to collect ADR reports which are forwarded to the Uppsala Monitoring Centre in Sweden, a centre for international service and scientific research towards patient safety [21]. Till date, the ADR reporting system does not involve community pharmacists and consumers and depends on voluntary reporting from other healthcare professionals, predominantly doctors, hospital pharmacists and nurses [22].

\section{Rationale of the study}

Factors like knowledge about medicines, cost of medicines, regulatory systems, laws, cultural issues and community beliefs can influence medicine use by consumers. They can also be influenced by the commercial promotion of medicines and communication with the prescriber and dispenser [20]. Nepal has many medicine use problems, for example: polypharmacy, use of expired drugs, irrational combination drugs, and overuse of antibiotics, vitamins/herbal remedies and prescribing using 
brand names $[13,14]$. These combined with lack of information to patients about the proper handling and use of drugs can lead to serious consequences like ADRs and interactions [14]. Studies show that community pharmacists may have an important role in pharmacovigilance $[3,23]$. To participate effectively however, community pharmacists should have adequate knowledge and proper attitudes towards pharmacovigilance. The present study has the objective of evaluating knowledge and attitude of community pharmacists regarding pharmacovigilance and consumer pharmacovigilance and compares the scores among different subgroups before, immediately after and six weeks following an educational intervention.

\section{Methods}

\section{Study site and study period}

The study was conducted from August 2014 to June 2015 among community pharmacists in Lalitpur district, one of the seventy-five districts of Nepal. The district, with Patan as its headquarters, covers an area of $385 \mathrm{~km}^{2}$ and is one of the three districts in the Kathmandu Valley, along with Kathmandu and Bhaktapur. Its population was 466,784 in the initial 2011 census tabulation [7]. Lalitpur District has two medical colleges, various other colleges and other institutions of higher learning [7].

\section{Study design}

The design was cross sectional conducted at three points in time, before, immediately after and 6 weeks following an educational intervention and the study population was community pharmacists registered with the Nepal Chemist and Druggist Association (NCDA) at Lalitpur district [24].

\section{Sampling method}

The pharmacy shops were selected using systematic sampling with a sampling interval of three where the first pharmacy was selected randomly between one and three. The sampling interval was three as we were selecting 75 pharmacies from the 204 registered community pharmacies in the district.

\section{Sample size calculation}

For sample size calculation, we assumed that the knowledge would be about $40 \%$ in our population of community pharmacists. This was obtained from the results of the pilot test and also from the literature review [25].

$$
\begin{aligned}
& \text { Knowledge }=40 \% \mathrm{p}=0.4, \mathrm{q}=1-\mathrm{p}=0.6 \\
& \mathrm{~N}=\left[\mathrm{Z} \alpha^{2} \times \mathrm{p} \times \mathrm{q} /(\text { M.E. })^{2}\right]
\end{aligned}
$$

where $\mathrm{Z} \alpha=1.645$ from normal table, two tailed at $10 \%$ alpha or $90 \%$ confidence interval, $\mathrm{P}=$ Population proportion, M.E $=$ Margin of error $=10 \%$, So, $\mathrm{n}=(1.645)^{2} \times(0.4) \times(0.6) /(0.1)^{2}=65$

Non response rate $=10 \%$

Total sample size required after provision for drop outs from the study $=65+10 \%$ of $65=71$

\section{Development of the questionnaire}

The questionnaire included questions framed based on knowledge and attitude studies about pharmacovigilance and consumer pharmacovigilance conducted among community pharmacists in other countries. Manuscripts and published papers describing similar research and methodological issues were also studied [4, 27-30]. In the questionnaire, the issues addressed were the origin of pharmacovigilance in Nepal, progress and status of pharmacovigilance and the present system of pharmacovigilance in the country. Information about reporting ADRs, who can report ADRs, location and functions of the national pharmacovigilance center were also covered. Processing of ADRs and information about the scales used to analyze ADRs were also addressed in the questionnaire.

\section{Translation of the questionnaire}

Additional file 1 shows the questionnaire developed in English. This questionnaire was translated into the Nepali language by two independent translators fluent in both languages and not associated with the study. The questionnaire was then back translated into English by two different individuals and the back translated version was compared with the original.

\section{Pretesting of the questionnaire}

The questionnaire was tested for readability and ease of understanding among ten CPs (four rural and six urban). The data obtained was not included in the study. Face validation of the questionnaire was conducted by colleagues in the department. Then the questionnaire was sent to faculties of other departments for their inputs regarding readability and grammatical errors. Content validation was done by sending the questionnaire to content experts of pharmacovigilance within the country. Internal consistency was measured by calculating Cronbach's alpha value, which was 0.67 indicating good reliability.

\section{Demographics}

Gender, age, work experience, educational qualification and the location of the pharmacy were noted. Participant's knowledge and attitude about pharmacovigilance and consumer pharmacovigilance was measured by 
noting his/her agreement with a set of 21 statements using a Likert-type scale.

\section{Information about the pharmacy}

Information about the year of registration, number of patients visiting the pharmacy daily, number of books available for reference in the pharmacy, number of dispensers and total number of brands of medicines in the pharmacy were noted from the respondents.

\section{Scoring system}

The scoring system used was: $5=$ strongly agree with the statement, $4=$ agree, $3=$ neutral, $2=$ disagree and $1=$ strongly disagree with the statement using a Likert scale. There were twelve statements for assessing knowledge (maximum possible score of 60 ), and nine statements for attitude (maximum possible score of 45). The maximum possible overall score obtained by adding the 'knowledge', and 'attitude' scores was 105 . The median and interquartile range were calculated for the 'knowledge,' 'attitude' and "overall" scores.

\section{Conduct of the study}

The questionnaire was administered personally by one of the investigator (RBP) visiting pharmacies in the study area. The community pharmacists were requested to complete the questionnaire in the presence of the investigator who could take back the completed questionnaire for analysis. This was used for collecting the baseline or pre intervention data. For the post intervention data, the questionnaire were administered to the participants immediately after the intervention session. Retention data were collected by visiting the participants individually in the same pharmacies 6 weeks after the educational intervention and employing the same procedure as that used for the pre-intervention data. Baseline knowledge and attitude of CPs was studied so that strengths and deficiencies could be noted and appropriate educational interventions planned. Knowledge and attitude was measured immediately after the educational intervention, and retention of information was tested 6 weeks post intervention.

\section{Educational intervention}

The intervention included a session about pharmacovigilance and consumer pharmacovigilance. They were also asked to share their views and opinions about the adverse drug reaction reporting form designed for community pharmacists. Informative posters were also displayed for information sharing about ADRs. Participants also learned about the existing pharmacovigilance system in Nepal and the importance of involving consumers in the existing system. The duration of the session was $2 \mathrm{~h}$. The teaching learning aids used were power point presentation, posters and leaflets about ADRs. The session was interactive and the participants designed an adverse drug reaction reporting form to be used by community pharmacists in the Nepali language.

\section{Statistical analysis}

The knowledge, attitude and overall scores were tested for normality of distribution using Shapiro-Wilk test. The samples were noted not to follow a normal distribution so median and interquartile range and Wilcoxon Signed Rank Tests for Repeated Samples (non-parametric test) were used for comparing pre, post and retention scores. A p value less than 0.05 was taken as statistically significant. As the sample size was small KAP scores at the three points in time were compared only among a limited number of subgroups. The scores were compared among respondents grouped according to gender, location and qualifications as we felt these were the most important characteristics and there was enough number of respondents in each subgroup. The collected data was analyzed using SPSS version 20.0 for Windows.

\section{Ethical considerations}

The study was approved by the Institutional Research Committee of KIST Medical College. All CPs were informed and explained about the aims and objectives of the study and invited to participate. Written informed consent was obtained from all participants.

\section{Results}

Seventy-five of the 86 invited respondents participated and the response rate was $87 \%$. Table 1 shows the respondent's demographic characteristics. Male respondents were greater in number compared to females and respondents of age group 21-30 years were more than respondents from other age groups. Thirty-five respondents (46\%) used Current Index of Medical Specialties (CIMS) as a reference book in the pharmacy while 13 respondents (17\%) used Nepal drug review (NDR) as their reference. Twenty-five respondents (30\%) had two people for dispensing medicines whereas a single person for dispensing was seen with 21 (28\%) respondents. These people were alwayszfzfs present in the pharmacy.

Table 2 shows the knowledge, attitude and total (overall) scores at pre, post and retention stages with regard to the educational intervention for the participants. The knowledge score increased both immediately after and six weeks following the intervention. The overall score decreased 6 weeks post-intervention as attitude score had decreased significantly during the period.

Table 3 shows differences in overall, knowledge and attitude scores at pre, post and retention stages of the 
Table 1 Demographic characteristics of respondents $(n=75)$

\begin{tabular}{ll}
\hline Characteristic & Number (percentage) \\
\hline Gender & \\
Male & $45(60)$ \\
Female & $30(40)$ \\
Age (in years) & \\
Below 20 & $12(16)$ \\
$21-30$ & $39(52)$ \\
$>3$ & $24(32)$ \\
Work experience (year) & \\
$<5$ & $23(30.6)$ \\
$5-10$ & $25(33.4)$ \\
$>10$ & $27(36)$ \\
Location & \\
Rural & $40(53.3)$ \\
Urban & $35(46.7)$ \\
Reference books available in the pharmacy & \\
CIMS & $35(46.6)$ \\
NDR & $13(17.4)$ \\
Both CIMS and NDR & $16(21.4)$ \\
None & $11(14.6)$ \\
\hline
\end{tabular}

educational intervention according to gender and location of the community pharmacists as these variables had more than 30 samples in each category.

\section{Gender}

The median knowledge scores improved immediately after the intervention and also six weeks following the educational intervention compared to the baseline among both genders. Males showed a consistent improvement in knowledge scores. Attitude scores improved after the intervention compared to baseline but the improvement was not significant 6 weeks after intervention among females. The overall scores also improved significantly after the intervention.

\section{Rural and urban location}

Knowledge scores among community pharmacists working at rural and urban pharmacies improved significantly immediately after and 6 weeks post intervention. The attitude scores post intervention also improved but the improvement was higher among pharmacists working in rural areas. The overall scores improved significantly immediately post intervention.

\section{Discussion}

The knowledge of community pharmacists in the present study regarding pharmacovigilance was low (47.5\%). The topic of consumer pharmacovigilance was also new and not many were aware about it. This finding was similar to that observed in previous studies [26-31]. Community pharmacy practice is well developed in nations like the United Kingdom and Australia, where pharmacists are well aware of pharmacovigilance and consumer pharmacovigilance systems [32].

A possible reason for the low knowledge and attitude scores in the present study could be that not all persons working in community pharmacies were from the pharmacy profession. Some were nurses, community medicine auxiliaries (CMAs) while others were pharmacy professionals. CMAs are paramedical professionals who undergo basic medical training for eighteen months. They are capable of diagnosing and treating minor illnesses and can also refer the patients for higher specialized care services if needed and they do not have any legal authority to dispense medicines unless they have completed the DDA orientation training course [18]. In the existing pharmacovigilance system of Nepal, pharmacists are allowed to report ADRs in the hospital settings through the regional pharmacovigilance centres, but it has not yet being started for community settings. Inadequate knowledge of ADR reporting systems among community pharmacists has also been reported in the literature. In Saudi Arabia, 86.8\% of community pharmacists surveyed were not aware of the country's ADRs reporting program, and another study in Iran indicated that only $30 \%$ of pharmacists were aware about the Iranian pharmacovigilance centre [33-35].

Community pharmacists should be educated about pharmacovigilance in Nepal to improve their knowledge. Lack of knowledge about what is an adverse drug reaction, what is to be reported, who can and should report, when to report, how to report, where to report, whom to report and lack of availability of ADR reporting forms for community pharmacists as well as for consumers can hamper ADR reporting in community settings. The

Table 2 Differences in knowledge, attitude and total (overall) (shown as median (interquartile range) scores at pre, post and retention stages of the educational intervention

\begin{tabular}{lllllllrrr}
\hline Domain & Pre & Post & p value & Pre & Retention & p value & Post & Retention & p value \\
\hline Knowledge & $39(44-46)$ & $44(44-44)$ & $<0.001$ & $41(40-41)$ & $46(43-46)$ & $<0.001$ & $46(46-46)$ & $53(49-53)$ & 0.254 \\
Attitude & $42(40-44)$ & $45(44-46)$ & $<0.001$ & $42(40-44)$ & $35(34-36)$ & $<0.001$ & $45(44-46)$ & $35(34-36)$ & $<0.001$ \\
Overall & $81(75-83)$ & $89(86-92)$ & $<0.001$ & $81(75-83)$ & $80(77-83)$ & 0.901 & $89(86-92)$ & $80(77-83)$ & $<0.001$ \\
\hline
\end{tabular}


Table 3 Difference in scores among selected subgroups of community pharmacists before (pre-test), immediately after (post-test) and six weeks following (retention) an educational intervention

\begin{tabular}{|c|c|c|c|c|c|c|c|c|c|}
\hline $\begin{array}{l}\text { Character- } \\
\text { istics }\end{array}$ & $\begin{array}{l}\text { Pre-test } \\
\text { median } \\
\text { (interquartile } \\
\text { range) }\end{array}$ & $\begin{array}{l}\text { Post-test } \\
\text { median } \\
\text { (interquartile } \\
\text { range) }\end{array}$ & p value ${ }^{\Delta}$ & $\begin{array}{l}\text { Pre-test } \\
\text { median } \\
\text { (interquartile } \\
\text { range) }\end{array}$ & $\begin{array}{l}\text { Retention } \\
\text { median } \\
\text { (interquartile } \\
\text { range) }\end{array}$ & p value ${ }^{\Delta}$ & $\begin{array}{l}\text { Post-test } \\
\text { median } \\
\text { (interquartile } \\
\text { range) }\end{array}$ & $\begin{array}{l}\text { Retention } \\
\text { median } \\
\text { (interquartile } \\
\text { range) }\end{array}$ & p value ${ }^{\Delta}$ \\
\hline \multicolumn{10}{|l|}{ Overall score } \\
\hline \multicolumn{10}{|l|}{ Gender } \\
\hline Male & $81(75-83)$ & 89 (85-92) & $<0.0$ & $81(75-83)$ & $80(77-83)$ & 1.000 & $89(85-92)$ & $80(77-83)$ & $<0.001$ \\
\hline Female & $80(75-83)$ & $91.5(81-93)$ & $<0.001$ & $80(75-83)$ & $80(75-82)$ & 0.769 & $91.5(81-93)$ & $80(75-82)$ & $<0.001$ \\
\hline \multicolumn{10}{|l|}{ Location } \\
\hline Rural & $80(75-93)$ & $90(87-92.75)$ & $<0.001$ & $80(75-93)$ & $81(79-93)$ & 0.168 & $90(87-92.75)$ & 81 (79-93) & $<0.001$ \\
\hline Urban & $82(76-86)$ & $89(85-92)$ & $<0.001$ & $82(76-86)$ & $80(75-93)$ & 0.267 & $89(85-92)$ & $80(75-93)$ & $<0.001$ \\
\hline \multicolumn{10}{|c|}{ Knowledge score } \\
\hline \multicolumn{10}{|c|}{ Gender } \\
\hline Male & $39(37-40)$ & $44(41-47)$ & $<0.001$ & $39(37-40)$ & $46(42-48)$ & $<0.001$ & $44(41-47)$ & $46(42-48)$ & 0.097 \\
\hline Female & $39(37-42)$ & $44(43-45)$ & $<0.001$ & $39(37-42)$ & $45(39-47)$ & $<0.001$ & $44(43-45)$ & $45(39-47)$ & 0.837 \\
\hline \multicolumn{10}{|l|}{ Location } \\
\hline Rural & $39(44-46)$ & $44(44-44)$ & $<0.001$ & $39(44-46)$ & $46(43-47)$ & $<0.001$ & $44(44-44)$ & $46(43-47)$ & 0.206 \\
\hline Urban & $38(33-46)$ & $43(43-44)$ & $<0.002$ & $38(33-46)$ & $46(42-47)$ & $<0.001$ & $43(43-44)$ & $46(42-47)$ & 0.761 \\
\hline \multicolumn{10}{|c|}{ Attitude score } \\
\hline \multicolumn{10}{|c|}{ Gender } \\
\hline Male & $43(37-44)$ & $44(43-47)$ & 0.012 & $43(37-44)$ & $35(31-37)$ & 0.003 & $44(43-47)$ & $35(31-37)$ & $<0.001$ \\
\hline Female & $41(35-44)$ & $46(44-48)$ & $<0.001$ & $41(35-44)$ & $35(31-37)$ & $<0.001$ & $46(44-48)$ & $35(31-37)$ & $<0.001$ \\
\hline \multicolumn{10}{|l|}{ Location } \\
\hline Rural & $41(35-44)$ & $45(43-47)$ & $<0.001$ & $41(35-44)$ & $35(31-38)$ & $<0.001$ & $45(43-47)$ & $35(31-38)$ & $<0.001$ \\
\hline Urban & $43(38-44)$ & $45(43-48)$ & 0.039 & $43(38-44)$ & $34(31-37)$ & $<0.001$ & $45(43-48)$ & $34(31-37)$ & $<0.001$ \\
\hline
\end{tabular}

$\Delta$ Wilcoxon Signed rank test

national pharmacovigilance program should use various interventional strategies followed by other countries for improving ADR reporting [36-40].

In our study, the attitude scores were good. In a study done by Khalili et al. [43], the attitude towards ADR reporting among community pharmacists improved after an intervention which has some similarities with studies done in the UK and other countries [11, 41-43], where pharmacists showed positive attitude towards ADR reporting. However, a study in Gujarat, India exploring KAP scores regarding pharmacovigilance among community pharmacists revealed a poor score and the authors had recommended an educational intervention [44].

The results of our study has shown that the educational program was effective in improving the knowledge and attitude of CPs towards pharmacovigilance. Similar findings were reported by previous studies $[43,45]$. A statistical difference was noted between respondents' gender and the responses to the statement adverse drug reactions are one of the major causes of death in the world and for the sentence about verbal reporting and written forms being preferred methods for ADR reporting $(\mathrm{p}<0.001)$. Significant differences were also seen with the statement regarding involvement of Pharmaceutical industries in reporting ADRs and about the location of the national pharmacovigilance centre. Participant's age, work experience, involvement in any kind of educational intervention has shown an impact on pharmacovigilance activities and ADR reporting as shown in other studies [30, 43, 45].

The baseline knowledge and attitude scores for both males and females were nearly same but the scores were better in females after the intervention. This was similar to that seen in a study done in Oman [46].

\section{Limitations}

The study participants were from Lalitpur district and the result may not be generalizable to pharmacists other districts. Involving more pharmacist from the other two districts of the Kathmandu valley (Kathmandu and Bhaktapur) would have given a better understanding about the perception of community pharmacists from the valley. Also the overall sample was small and the intervention may not have been the only factor which changed attitudes, as no control group was used. Also some of the 
statements in the questionnaire were positive and may have influenced the participants' response.

\section{Conclusion}

The educational intervention improved the pharmacovigilance knowledge and attitude scores of the community pharmacists. The present study revealed an improvement in the knowledge scores for males and female participants whereas, the attitude scores improved among female respondents. Knowledge and attitude scores were higher among pharmacists working in rural areas.

Similar studies should be conducted among community pharmacists in other districts of Nepal. The perception of consumers regarding reporting ADRs to community pharmacists should also be studied.

\section{Additional file}

Additional file 1. Questionnaire used in the study.

\begin{abstract}
Abbreviations
ADR: adverse drug reaction; CIMS: current index of medical specialties; HCP: Health care professionals; CP: community pharmacists; GDP: gross domestic product; DDA: Department of Drug Administration; NCDA: Nepal Chemist and Druggist Association; SPSS: statistical package for social sciences; NDR: Nepal drug review; NGO: Non-governmental organization; CMA: community medicine auxiliary; B.Pharm: Bachelor in pharmacy; M.Pharm: Masters in pharmacy; D.Pharm: Diploma in pharmacy.
\end{abstract}

\section{Authors' contributions}

NJ, DSR and PRS conceived and designed the study. PRS, DSR and SB finalized the methodology and tools used. NJ, RBP collected the data. PRS, SB analysed the data and MA, NJ and PRS drafted the manuscript. All the authors made significant contributions to writing the manuscript and reviewing the literature. All authors read and approved the final manuscript.

\section{Author details}

${ }^{1}$ Department of Clinical Pharmacology and Therapeutics, KIST Medical College, Lalitpur, Nepal. ${ }^{2}$ Department of Pharmacy, NIMS University, Jaipur, Rajasthan, India. ${ }^{3}$ Department of Pharmacology, Xavier University of School of Medicine, Oranjestad, Aruba. ${ }^{4}$ Department of Community Health Sciences, School of Medicine, Patan Academy of Health Sciences, Kathmandu, Nepal. ${ }^{5}$ KIST Medical College, Lalitpur, Nepal. ${ }^{6}$ Department of Pharmacology, Manipal College of Medical Sciences, Pokhara, Nepal. ${ }^{7}$ Department of Pharmacy, Aden University, Aden, Yemen.

\section{Acknowledgements}

The authors takes this opportunity to thank all the participants of the study. We also like to thank Ms. Omi Bajracharya, faculty from the department of Clinical Pharmacology and Therapeutics, Ms. Sunita Panta, the office assistant and Asish Thapa, Intern student and KIST Medical College management for helping to conduct the educational intervention session at KIST Medical College, Imadol.

\section{Competing interests}

The authors declare that they have no competing interests.

\section{Availability of data and materials}

The data files will be made available on request from the corresponding author.

\section{Consent to publish}

All authors have consented to publish the manuscript in BMC Research Notes and all authors have read and approved the different revised versions and the final submitted version of the manuscript.

\section{Ethical considerations}

This study was approved by the Institutional Research Committee of KIST Medical College. The letter issued for the approval was numbered as 0054/2014/15. All participants were informed about the aims and objectives of the study and invited to participate. Written informed consent was obtained from all interested participants.

\section{Funding}

Authors acknowledge Nepal Academy of Science and Technology (NAST), Khumaltar, Nepal for funding this research.

Received: 17 November 2015 Accepted: 14 December 2016

Published online: 03 January 2017

\section{References}

1. Jha N, Rathore DS, Shankar PR, Thapa BB, Bhuju G, Alshakka M. Need for involving consumers in Nepal's pharmacovigilance system. Australas Med J. 2014;7:191-5.

2. Palaian S, Izham MIM, Mishra P. Evaluation of the knowledge, attitude and practices on adverse drug reactions and pharmacovigilance among healthcare professionals in a Nepalese hospital-a preliminary study. Int J Pharmacol. 2007:6:1.

3. Bhuvan KC, Alrasheedy AA, Mohamed MI. Do community pharmacists in Nepal have a role in adverse drug reaction reporting systems? Australas Med J. 2013;6:100-3.

4. Palaian S, Ibrahim MIM, Mishra P. Pattern of adverse drug reactions reported by the community pharmacists in Nepal. Pharm Pract (Granada). 2010;8:201-7.

5. Nepal in Figures 2010. Central Bureau of Statistics (CBS), Government of Nepal; 2010. http://www.cbs.gov.np. Accessed 12 Sept 2015.

6. World Health Organization (WHO). "World Health Statistics 2010"; 2010. http://www.who.int/whosis/whostat/2010/en/index.html. Accessed 25 Sept 2015.

7. Fact Sheet on Nepal; Asian Development Bank. http://www.adb.org. Accessed 12 Sept 2015

8. Ministry of Health and Population, World Health Organization. Nepal pharmaceutical country profile. Kathmandu; 2011. http://un.info.np/Net/ NeoDocs/View/4794. Accessed 11 Sept 2015.

9. Harmark L, van Grootheest AC. Pharmacovigilance methods, recent developments and future perspectives. Eur J Clin Pharmacol. 2008:64:743-52.

10. Lopez-Gonzalez E, Herdeiro MT, Figueiras A. Determinants of underreporting of adverse drug reactions: a systematic review. Drug Saf. 2009;32:19-31.

11. Irujo M, Beitia G, Bes-Rastrollo M, Figueiras A, Hernandez-Diaz S, Lasheras B. Factors that influence under-reporting of suspected adverse drug reactions among community pharmacists in a Spanish region. Drug Saf. 2007:30:1073-82.

12. Bhuvan KC, Subish P, Mohamed MI. PharmD education in Nepal: challenges ahead. Am J Pharm Educ. 2011;75(2):38c

13. Kafle KK, Gartoulla RP, Pradhan YM, Shrestha AD, Karkee SB, Quick JD. Drug retailer training: experiences from Nepal. Soc Sci Med. 1992;35:1015-25.

14. Shankar PR, Partha P, Shenoy N. Self-medication and nondoctor prescription practices in Pokhara valley, Western Nepal: a questionnaire-based study. BMC Fam Pract. 2002;3:17.

15. An approach of quality health service to the community. Nepal Pharm Counc News Lett. 2005;3(1):1-3. http://nepalpharmacycouncil.org.np/ downloads/Newsletter_V1_2005.pdf. Accessed 14 Oct 2015.

16. Drug Act 2035. Department of Drug Administration, Nepal; 1978. http:// www.dda.gov.np/drugact.php. Accessed 13 Sept 2015.

17. Nepal Pharmacy Council. http://nepalpharmacycouncil.org.np/. Accessed 25 Sept 2015 
18. Gyawali S, Rathore DS, Adhikari K, Shankar PR, Vikash KC, Basnet S. Pharmacy practice and injection use in community pharmacies in Pokhara city, Western Nepal. BMC Health Serv Res. 2014;13:3.

19. Blum NL. Rational pharmaceutical management project United States Pharmacopoeia. Drug information Development. A case study, Nepal. http://www.usp.org/pdf/EN/dqi/nepalCaseStudy.pdf. Accessed 20 July 2015.

20. Ahmed AM, Ibrahim MIM, Subish P. Importance of consumer pharmacovigilance system in developing countries: a case of Malaysia. J Clin Diagn Res. 2010;4:2929-35.

21. World Health Organization. Nepal joins programme. Uppsala Rep. 2007;36:5-6. http://who-umc.org/graphics/24365.pdf. Accessed 20 July 2015.

22. Jha N, Rathore DS, Shankar PR, Gyawali S, Alshakka M, Bhandary S. An educational intervention's effect on healthcare professionals'attitudes towards pharmacovigilance. Australas Med J. 2014;7:478-89.

23. Leone R, Moretti U, D'Inacau P, Conforti A, Margo L, Lora R, et al. Effect of pharmacist involvement on patients reporting of adverse drug reactions: first Italian study. Drug Saf. 2013;36(4):267-76.

24. DDA. DDA Registered pharmacy list. Lalitpur: Department of Drug Administration; 2006. www.dda.gov.np/pharmacy\%20_registration/lalitpur.pdf Accessed 19 Sept 2015.

25. Praveen S, Prakash RJ, Manjunath GN, Gautham MS, Kumar N. Adverse Drug Reaction reporting among medical and dental practitioners: a KAP study. Indian J Med Spec. 2013;4:10-5.

26. Alshakka MA, Izham Ml, Azmi AH. Do health care professionals have positive perception towards consumers reporting adverse drug reactions? J Clin Diagn Res. 2013;7:2181-5

27. Sundos Q, Zakia M, Mohammed S, Yassin AH. Reporting adverse drug reactions: evaluation of knowledge, attitude and practice among community pharmacists in UAE. IOSR J Pharm. 2014;4:17-23.

28. Graille V, Lapeyre-Mestre M, Montastruc JL. Drug vigilance: opinion survey among residents of a university hospital. Therapie. 1994:49:451-4.

29. Hasford J, Goettler M, Munter KH, Müller-Oerlinghausen B. Physicians' knowledge and attitudes regarding the spontaneous reporting system for adverse drug reactions. J Clin Epidemiol. 2002;55:945-50.

30. Figueiras A, Herdeiro M, Polonia J, Gestal-Otero J. An educational intervention to improve physician reporting of adverse drug reactions: a cluster-randomized controlled trial. J Am Med Assoc. 2006;296:1086-93.

31. Sorokin R, Claves JL, Kane GC, Gottlieb JE. The near miss resident conference: understanding the barriers to confronting medical errors. Semin Med Pract. 2002;5:17.

32. Green CF, Mottram DR, Rowe PH, Pirmohamed M. Attitudes and knowledge of hospital pharmacists to adverse drug reaction reporting. $\mathrm{Br} \mathrm{J}$ Clin Pharmacol. 2001;51:81-6.
33. Vessal G, Mardani Z, Mollai M. Knowledge, attitudes, and perceptions of pharmacists to adverse drug reaction reporting in Iran. Pharm World Sci. 2009:31:183-7.

34. Bawazir SA. Attitude of community pharmacists in Saudi Arabia towards adverse drug reaction reporting. Saudi Pharm J. 2006;14:75-83.

35. Mahmood MA. Community pharmacists' knowledge, behaviors and experiences about adverse drug reaction reporting in Saudi Arabia. Saudi Pharma J. 2013;7:1-5. doi:10.1016/j.jsps.2013.07.005.

36. Evans SM, Berry JG, Smith BJ, Esterman A, Selim P, OShaughnessy J, et al. Attitudes and barriers to incident reporting: a collaborative hospital study. Qual Saf Health Care. 2006;15:39-43.

37. Ting KN, Stratton-Powell DM, Anderson C. Community pharmacists' views on adverse drug reactions reporting in Malaysia: a pilot study. Pharm World Sci. 2010;32:339-42.

38. Gedde A, Harg P, Stenberg H, Buajordet M, Granas AG, Horn AM. Characteristics and quality of adverse drug reaction reports by pharmacists in Norway. Pharmacoepidemiol Drug Saf. 2007;16:999-1005.

39. Granas AG, Buajordet M, Stenberg-Nilsen H, Harg P, Horn AM. Pharmacists' attitudes towards the reporting of suspected adverse drug reactions in Norway. Pharmacoepidemiol Drug Saf. 2007;16:429-34.

40. Sweis D, Wong IC. A survey on factors that could affect adverse drug reaction reporting according to hospital pharmacists in Great Britain. Drug Saf. 2000;23:165-72

41. Sevene E, Mariano A, Mehta U, Machai M, Dodoo A, Vilardell D, et al. Spontaneous adverse drug reaction reporting in rural districts of Mozambique. Drug Saf. 2008;31:867-76.

42. Christensen ST, Sondergaard B, Honore PH, Bjerrum OJ. Pharmacy student driven detection of adverse drug reactions in the community pharmacy setting. Pharmacoepidemiol Drug Saf. 2011;20:399-404.

43. Khalili H, Mohebbi N, Hendoiee N, Keshtkar A, Khavidaki SD. Improvement of knowledge, attitude and perception of healthcare workers about ADR, a pre- and post-clinical pharmacists' interventional study. BMJ Open. 2012:2:e000367.

44. Rathod K, Panchal A. Knowledge, attitude and practice of community pharmacists of Gujarat towards adverse drug reactions. Int Arch Integr Med. 2014;1(1):18-25.

45. Ramadan ME, Mohamed AH, Mohamed IM. Impact of educational intervention for improving pharmacist knowledge in adverse drug reactions (adr) reporting: experience from Malaysia. Open Drug Saf J. 2011;2:47-53.

46. Jose J, Jimmy B, AIGhailani AS, Al Majali MA. A cross sectional pilot study on assessing the knowledge, attitude and behavior of community pharmacists to adverse drug reaction related aspects in the Sultanate of Oman. Saudi Pharm J. 2014;22:163-9.

\section{Submit your next manuscript to BioMed Central and we will help you at every step:}

- We accept pre-submission inquiries

- Our selector tool helps you to find the most relevant journal

- We provide round the clock customer support

- Convenient online submission

- Thorough peer review

- Inclusion in PubMed and all major indexing services

- Maximum visibility for your research

Submit your manuscript at www.biomedcentral com/submit
BioMed Central 